Gut, 1989, 30, 1419-1423

Case report

\title{
Development of chronic hepatocerebral degeneration eight years after a distal splenorenal (Warren) shunt
}

\author{
A F BLEASEL, R C WAUGH, AND G W McCAUGHAN
}

From the Departments of Neurology, Radiology and the A W Morrow Gastroenterology and Liver Centre, Royal Prince Alfred Hospital, Sydney, Australia

SUMmaRy It is well known that chronic encephalopathy may be a major complication after the establishment of a surgical portal caval shunt for an episode of variceal haemorrhage. In an effort to minimise this problem Warren and colleagues' ${ }^{1}$ developed the distal splenorenal shunt where the portal and mesenteric blood flow to the liver was left intact. It is now recognised, however, that the longterm incidence of encephalopathy may be no different with this type of shunt compared with conventional surgical portal systemic shunts. ${ }^{2}$ Acquired chronic hepatocerebral degeneration ${ }^{3}$ has not been reported after such a selective shunt. A patient with primary biliary cirrhosis is reported who developed the clinical features of this syndrome eight years after a successful distal splenorenal shunt.

\section{Case history}

A 53 year old woman with primary biliary cirrhosis was referred for assessment regarding liver transplantation in July 1987. The patient had rheumatoid arthritis diagnosed in 1969 and during routine biochemical screening she was noticed to have a serum alkaline phosphatase of $875 \mu \mathrm{mol} / \mathrm{l}$. In June 1978 she had a haematemesis and melaena whilst taking nonsteroidal anti-inflammatory agents. Gastric erosions were shown by upper gastrointestinal tract endoscopy and oesophageal varices were noted at that time. A liver biopsy revealed features of primary biliary cirrhosis with established cirrhosis. The serum anti-mitochondrial antibodies (AMA) were strongly positive. She was treated with low dose Penicillamine. In October, 1978, she had a further haematemesis and melaena from bleeding oesophageal varices. The bleeding continued and a distal splenorenal (Warren) shunt was performed. The splenic vein was divided

Address for correspondence: G W McC aughan, A W Morrow Gastroenterology and Liver centre. Royal Prince Alfred Hospital. Missenden Road, Camperdown NSW 2050, Australia.

Accepted for publication 22 February 1989. and the distal end of the splenic vein was anastomosed in an end-to-side shunt to the renal vein. The left gastric (coronary) vein was also divided. She made an uneventful recovery. In 1980 she was found to be hypothyroid and thyroxine replacement therapy was begun. In 1982 thrombocytopenia led to the cessation of Penicillamine. Her liver function tests at this time revealed a normal bilirubin with a continually raised alkaline phosphatase. She had dry gritty eyes and a dry mouth. She was noted by her husband to be becoming vague and forgetful towards the end of 1986. About this time the patient began to experience involuntary grimacing, chewing and lip smacking movements of the face and mouth. She was admitted to hospital in June 1987 with peripheral oedema, hepatic encephalopathy and hypothyroidism. Her thyroxine stimulating hormone (TSH) was found to be $55.4 \mu \mathrm{mol} / \mathrm{l}$ (normal 0.5-4). Non-compliance with thyroxine therapy was suspected as the thyroid function tests improved with supervised treatment in hospital. Hepatic encephalopathy improved with lactulose syrup (lactulose $13 \cdot 36 \mathrm{~g}$, galactose $2 \cdot 2 \mathrm{~g}$ lactose $1.2 \mathrm{~g}$, epilactose $0.8 \mathrm{~g}$ ) however, she was noted to have a persistent dysarthria and ataxic gait. 
On admission to hospital she was jaundiced with multiple telangiectases of the skin. Foetor hepaticus was present but there was no asterixis. There was $5 \mathrm{~cm}$ of smooth hepatomegaly, $2 \mathrm{~cm}$ of splenomegaly and a soft abdomen with mild ascites. Temperature, pulse and blood pressure were normal. There was mild peripheral oedema but no other signs of cardiac failure although a systolic ejection murmur was present at the apex and left sternal edge. Short mental state examination at the bedside showed the patient to be alert and orientated with normal short term memory, general knowledge, ability to calculate and think abstractly. There was, however, evidence of constructional dyspraxia. She had an ataxic dysarthria and there was prominent buccolingual dyskinesia with facial grimacing and occasional involuntary shrugging of one or other shoulder. There was no nystagmus and KaiserFleicher rings were not present. Tone and power were normal in all limbs. Tests of co-ordination were normal in the upper limbs but heel-knee-shin testing was ataxic in the lower limbs. She walked unsteadily on a wide base and was unable to tandem walk. The Romberg's test was negative. Deep tendon reflexes were generally brisk and symmetrical, plantar responses were extensor. Sensation was normal.

Neuropsychological assessment showed the patient to be of average premorbid intelligence $(\mathrm{IQ}=$ 95-100). She had a normal immediate memory span (six digits forwards, five digits backwards). During the assessment she had some periods of mild confusion, although she certainly was not encephalopathic and when set on the right track would perform well. All dominant hemisphere (verbal) skills, including learning and memory, planning and organisation, abstraction and flexibility of thought, were found to be intact. She had a severe visuoperceptual and visuospatial deficit marked by very poor synthesis of visual material and very poor construction ability; she was not aided by having structure added to a task. There was, however, no evidence of visual agnosia and visual memory was intact.

Liver function tests revealed a total bilirubin of $199 \mu \mathrm{mol} / \mathrm{l}$ (normal range 0-18), albumin $26 \mathrm{~g} / \mathrm{l}$ (normal 40-52), alkaline phosphatase $594 \mathrm{U} / \mathrm{L}$ (normal <160), aspartate transaminase $128 \mathrm{U} / \mathrm{l}$ (normal 5-55), alanine transaminase $101 \mathrm{U} / \mathrm{l}$ (normal $5-55)$, gamma glutamyl transpeptidase $215 \mathrm{U} / \mathrm{l}$ (normal <55), cholesterol $5 \cdot 6 \mathrm{mmol} / 1$ (normal $<5 \cdot 2)$. Her haemoglobin was $13.0 \mathrm{~g} / \mathrm{dl}$ (normal 11.5-16.5), platelets $166 \times 10^{4} / 1$ (normal $150-500$ ), white cells $5 \cdot 4$ $\times 10^{4} / 1$ (normal $\left.4 \cdot 0-11 \cdot 0\right)$ Pre-albumin was low at 60 $\mathrm{mg} / \mathrm{l}$ (normal 150-400), serum copper was $22 \cdot 1 \mu \mathrm{mol} /$ 1 (normal $12-22$ ), urinary copper was $7 \cdot 0 \mu \mathrm{mol} / 24 \mathrm{~h}$ (normal 0.0-1.6), serum caeruloplasmin was $0.36 \mathrm{~g} / \mathrm{l}$ (normal $0 \cdot 2-0 \cdot 45)$. Vitamin $B_{12}$ was $>1500 \mathrm{ng} / \mathrm{l}$ (normal 200-800), serum folate was $3 \cdot 3 \mu \mathrm{g} / \mathrm{l}$ (normal 3:2-24). Immunological studies revealed an antimitochondrial antibody titre 1:640. The serum TSH on thyroid replacement therapy was $3.37 \mathrm{mlU} / \mathrm{l}$ (normal 0.5-4). Thyroxine and thyroid binding globulin were normal. Other investigations revealed a low vitamin A at $0.2 \mu \mathrm{mol} / \mathrm{l}$ (normal 1.4-4) and a low vitamin D25 of $11 \mathrm{nmol} / \mathrm{l}$ (normal 22-165). The vitamin E level was normal at $29 \mu \mathrm{mol} / \mathrm{l}$ (normal 830). There was evidence of mild thiamine (vitamin $B_{1}$ ) deficiency assessed by assay of erythrocyte transketolase activity (ETKA) before and after addition of thiamine pyrophosphate (TPP). ETKA 0.32 units (normal $0 \cdot 6-1 \cdot 3$ ) ETKA and TPP 0.39 units (normal $0 \cdot 7-1 \cdot 5$ ) TPP effect $24 \%$ (normal $0-18 \%)$. Her selenium level was slightly low at $0.74 \mu \mathrm{mol} / \mathrm{l}$ (normal $0 \cdot 8-1 \cdot 4$ ). The serum VDRL was negative.

The predominant background rhythm in the electroencephalogram was symmetrical low voltage fast activity in the beta range. There was a small

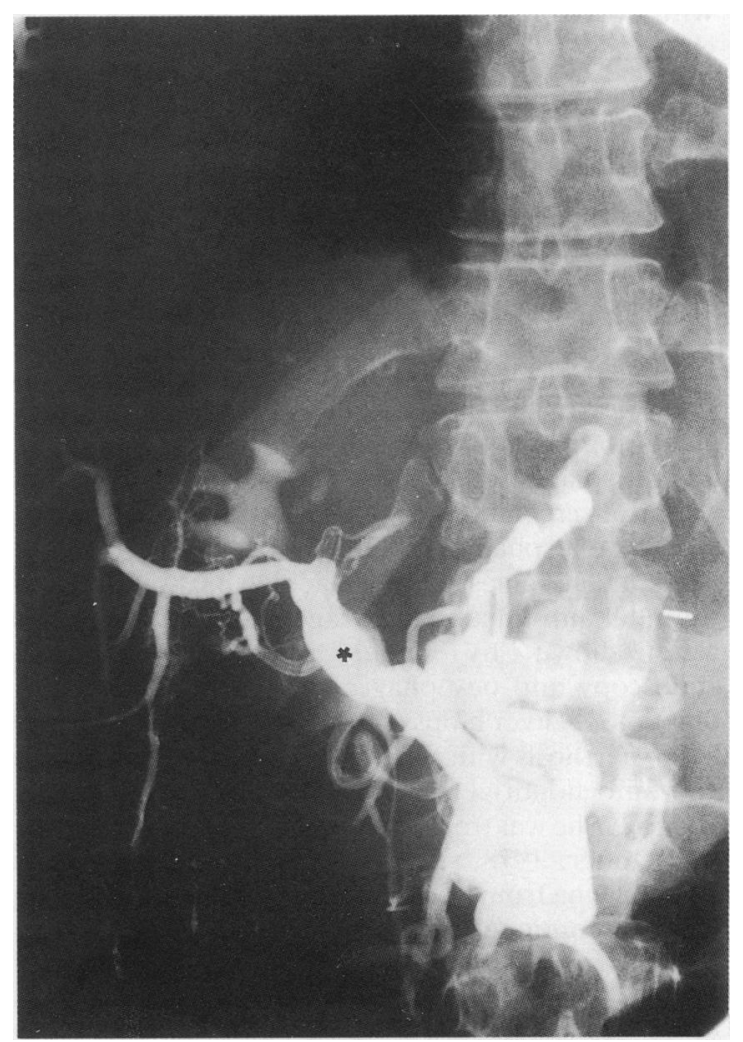

Fig. 1 Percutaneous hepatoportography showing an atrophic portal vein (identified by the asterisk) and no evidence of superior mesenteric vein filling. 


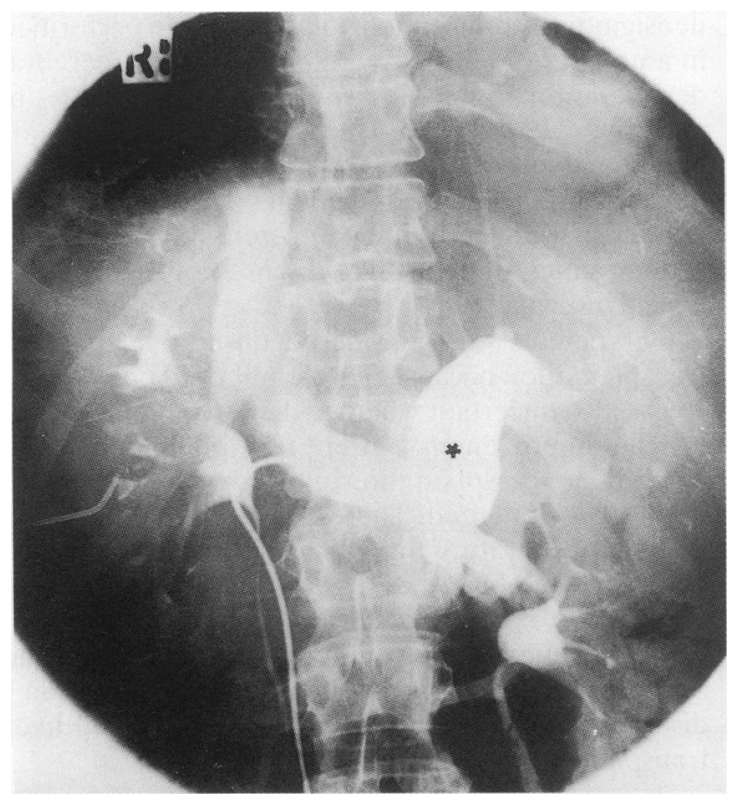

Fig. 2 Transfemoral catheterisation of the left renal vein showing a patent distal splenorenal shunt (identified by the asterisk).

amount of alpha rhythm. Intermittent $4-6 \mathrm{~Hz}$ theta activity was present over both temporal regions more marked on the left. There were no triphasic waves.

A computerised axial tomogram (CT) of the brain was performed using the General Electric 9800 scanner. Scans were done at $10 \mathrm{~mm}$ intervals through the brain without radiographic contrast injection. There were no abnormalities detected. A magnetic resonance imaging (MRI) scan of the brain was performed on the General Electric Sigma machine with a 1.5 telsa magnet. T1 weighted sagittal sections were performed followed by $\mathrm{T} 2$ weighted axial sections. Again no abnormalities were detected in the cerebral cortex, basal ganglia or cerebellum.

Selective arteriography and hepatoportography showed thrombosed portal and superior mesenteric veins. The portal vein was replaced by $2-3$ atrophic channels suggestive of cavernous transformation (Fig. 1). There were marked collaterals on late phase films which seemed to be arising from the proximal end of the splenic vein. Catheterisation through the renal vein showed a widely patent splenorenal shunt (Fig. 2).

Medications were cimetidine $400 \mathrm{mg}$ nocte, thyroxine $200 \mu \mathrm{g}$ mane, oral calcium supplements and spirnolactone $100 \mathrm{mg}$ mane. There was no history of phenothiazine intake. There was some subjective improvement in mental function and orofacial movements after the reintroduction of lactulose syrup $20 \mathrm{ml}$ tds and mild protein (less than $50 \mathrm{~g} /$ day) restriction.

\section{Discussion}

There is no doubt that this woman had longstanding primary biliary cirrhosis. Antimitochondrial antibodies were present at a significant titre, the histology of her liver biopsy was consistent with the diagnosis and she had characteristically associated auto-immune diseases such as rheumatoid arthritis, hypothyroidism and possibly Sjögrens syndrome. The patient's age, the negative family history, and the absence of Kayser-Fleischer rings do not themselves exclude Wilson's Disease. ${ }^{+}$Taken together, however, with a normal serum caeruloplasmin it is extremely unlikely that this woman has Wilson's disease in addition to primary biliary cirrhosis despite the raised urinary copper secretion. Hypothyroidism may be associated with ataxia, however, it improves with treatment' and our patient showed no change in her ataxia with correction of her hypothyroidism. It is possible that thiamine deficiency may have contributed to her ataxia" but this would not account for her other neurological symptoms and signs.

Chronic liver disease complicated by venous portal systemic shunting is often associated with chronic portal systemic encephalopathy. A fluctuating clinical course with intermittent hepatic encephalopathy, precipitated by gastrointestinal haemorrhage, protein loading or systemic illness, occurs most commonly. Less frequently symptoms and signs of intellectual and motor dysfunction persist in between reversible bouts of stupor or there appears to be a chronic progressive cerebral degeneration without a history of episodic disturbances of consciousness. ${ }^{3-4}$ The clinical features of this acquired (non-Wilsonian) hepatocerebral degeneration include cognitive impairment, dysarthria, cerebellar ataxia and involuntary movements. Coarse tremor, myoclonus and pyramidal tract signs may also occur. Neuropathological examination of the brain may show a patchy spongy degeneration with neuronal loss in the deeper layers of the cerebral cortex, basal ganglia and less often the cerebellum. ${ }^{3}$ A consistent finding, seen also in patients dying in acute hepatic failure and experimental models of hepatic encephalopathy, is that of a diffuse increase in size of protoplasmic astrocytes; Alzheimer Type II astrocytes."

Our patient had dysarthria, mild pyramidal tract signs and cerebellar ataxia of the lower limbs and gait. Apart from occasional involuntary shrugging of the shoulder, choreoathetoid movements of the limbs were not evident. She had marked buccolingual 
dyskinesia, however, and facial grimacing similar to that described in several other reports of chronic hepatocerebral degeneration." "II 12 Neuropsychological assessment did not show evidence of encephalopathy or dementia, instead the results indicated non-dominant parietal lobe dysfunction. In the majority of cases reported in the literature there has been evidence of global cognitive impairment and more discrete syndromes of agnosia, dysphasia or apraxia have not been described. This is somewhat surprising as focal motor or sensory signs may appear in a small number of cases. ${ }^{371.3}$ It is interesting that both a CT scan and an MRI scan of the brain were normal. Considering that discolouration and softening of areas of the cerebral cortex and lenticular nuclei may be visible on gross inspection of the brain " one might expect corresponding radiological abnormalities in these patients. There is, however, no good correlation between the severity of the neuropathological findings and the clinical picture in acquired hepatocerebral degeneration. ${ }^{3}$

Two of the 27 patients described by Victor, Adams and Cole ${ }^{3}$ had primary biliary cirrhosis, whilst 12 had established surgical portal systemic shunts. Five of these were splenorenal shunts in the era before the introduction of the Warren shunt. One of Finlayson and Superville's" patients had a splenorenal shunt (details are not given) but again it seems to have been done before the Warren shunts were in use. Although chronic encephalopathy is now well recognised after Warren shunts the development of the chronic hepatocerebral degeneration syndrome is not mentioned in follow up. ${ }^{1+15}$ Serial angiographic studies of patients after distal splenorenal shunts show that collaterals may develop and selectively is lost over varying periods of time..$^{16}$ In addition, portal vein thrombosis has been described in up to $10 \%$ of patients. ${ }^{17}$ Our patient had evidence of portal vein occlusion and marked collaterals between the portal/ mesenteric system and the splenorenal shunt. These features undoubtedly were important in the development of the patient's neurological illness.

There was some improvement in our patient's condition, particularly the orofacial dyskinesia, with protein restriction and lactulose syrup. Other groups have reported varying success with similar measures aimed at reducing the intraintestinal production of nitrogenous substances. Read et al found improvement in mental state occurred in some of their patients but other neurological signs did not change. Levy et al ${ }^{\text {1. }}$ reported improvement in cerebellar signs and choreoathetoid movements in addition to mental state in three of five cases of chronic hepatocerebral degeneration treated with low protein diet, neomycin, lactulose and levodopa. Colonic exclusion, achieved by colonic resection, ileosigmoidostomy or ileostomy, has been performed in a number of patients with chronic hepatocerebral degeneration and improvements reported in cognitive and motor function. "7" Such major abdominal surgery, however, has a high perioperative mortality in this group of patients. The prognosis of patients with acquired hepatocerebral degeneration is determined by their liver disease not their neurological disorder."

Our patient was considered unsuitable for liver transplantation because of a thrombosed portal vein. It was also uncertain whether there would be neurological improvement after transplantation. The response to transplantation of this type of condition is not well documented. There is a suggestion from one case in the literature that it may improve ${ }^{21}$ but others suggest little change despite normal graft function (David Van Theil, University of Pittsburgh, personal communication). It is of interest, however, that the severe neurological signs sometimes seen in Wilson's disease may slowly improve after a successful liver transplant..$^{21}$

We would like to acknowledge Dr Richard Johnson of the Gastroenterology Department, Royal Adelaide Hospital, South Australia for providing details of the patient's past history and investigations.

\section{Addendum}

We have also recently seen a very similar case two years after a distal splenorenal shunt. The patient had PBC with signs of buccolingual dyskinesia, facial grimacing and truncal ataxia. There were no pyramidal tract signs.

\section{References}

1 Warren WD, Zeppa R, Foman JJ. Selective transsplenic decompression of gastrocsophageal varices by distal spleno-veral shunt. Ann Surg 1967; 166: 437-5.5.

2 Henderson MJ. Variceal bleeding: which shunt?. [Editorial]. Gastroenterology 1986; 91: 1021-3.

3 Victor M, Adams RD, Cole M. The acquired (nonWilsonion) type of chronic hepatocerebral degeneration. Medicine (Balti) 1965; 44: 345-96.

4 Ross ME, Jacobson IM. Dienstag JI, Martin JB. Lateonset Wilson's disease with neurological involvement in the absence of Kayser-Fleicher rings. Ann Neurol 1985; 17: 411-3.

5 Cremer GM, Golstein NP, Paris J. Myxedema and ataxia. Neurology 1969; 19: 37-46.

6 Adams RD, Victor M. Diseases of the nervous system due to nutritional deficiency. In: Adams RD, Victor M. Principles of neurology 3rd ed. New York: McGrawHill Book Company, 1985: 760-86.

7 Read AE, Sherlock S, Laidlaw J, Walker JG. The neuro-psychiatric syndromes associated with chronic 
liver disease and an extensive portal-systemic collateral circulation. QJ Med 1967; 36: 135-50.

8 Plum F, Hindfelt B. The neurological complications of liver disease. In: Vinken PJ, Bruny GW. eds. Handbook of clinical neurology, Vol 27. Metabolic and deficiency diseases of the nervous system Part 1. Amsterdam: North-Holland Publ Co, 1976: 349-77.

9 Hoyumpa AM, Desmond PV, Avant GR, Roberts RK. Schenker S. Hepatic encephalopathy. Gastroenterology 1979; 76: 184-95.

10 Dievner NH. Glial and neuronal changes in experimental hepatic encephalopathy - quantitative morphological investigation. Acta Neurol Scand 1978; 58: $9-144$.

11 Finlaysan MH. Superville B. Distribution of cercbral lesions in acquired hepatocerebral degeneration. Brain 1981; 104: 79-95.

12 Toghill PJ, Johnson AW, Smith JF. Choreathetosis in porto-systemic encephalopathy. J Neurol Neurosurg Psychiatry 1967: 30: 358-63.

13 Sussman EB, Steinberg SS. Hereditary hemorrhagic telangiecstasia. A case with hepatocellular carcinoma and acquired hepatocerebral degeneration. Arch Pathol 1975; 99: 95-100.

14 Langer B, Taylor BR, MacKenzic DR, Gilas T, Stone RM, Blendis L. Further report of a prospective randomized trial comparing distal spleno-renal shunt with end to side portacaval shunt. Gastroenterology 1985; 88: 424-9.

15 Millikar WJ, Warren WD, Henderson JM, et al. The Emory prospective randomized trial: selective versus non-selective shunt to control variceal bleeding ten year follow up. Ann Surg 1985: 201: 712-22.

16 Belghih J, Greiner P. Novel O, Nahami H. Fekete F. Longterm loss of Warren`s shunt selectivity. Arch Surg 1981; 116: $1121-4$.

17 Henderson JM. Millikan WJ, Chippono J, et al. The incidence and natural history of thrombosis in the portal vein following distal splenorenal shunt. Ann Surg 1982; 196: $1-7$.

18 Levy VG, Cameron E, Ollat H. Opolon P. Darnis F. Centamin F. Perennial hepatic encephalopathies (acquired cerebral deterioration due to other causes than Wilson's discasc). Sem Hôp Paris 1983; 59: 136973.

19 Willson RA. Chronic refractory encephalopathy. Evaluation of an ilcostomy 22 years after a portacaval shunt. Dig Dis Sci 1981 26: 839-42.

20) Parkes JD, Murray-Lyons IM. Williams R. Neuropsychiatric and electroencephalographic changes after transplantation of the liver. QJ Med 1970; 39: 51.5-27.

21 Polsen RJ, Rolles K, Calne RY, Williams R, Marsden D. Reversal of severe neurological manifestations of Wilsons disease following orthotopic liver transplantation. QJ Med 1987; 64: 685-91. 